\title{
Sex Differences Between Primary and Secondary Psychopathy, Parental Bonding, and Attachment Style
}

\author{
Alyson Blanchard and Minna Lyons \\ University of Liverpool
}

\begin{abstract}
Sex differences in primary and secondary psychopathic traits and behaviors are consistently evidenced, although less is known about the developmental trajectories of these differences and why they might arise. In this study $(N=362)$ we investigated whether men and women reporting higher levels of primary or secondary psychopathic traits differed in retrospective accounts of how cold and controlling both their mother and father were during childhood, and how anxious and avoidant they are about contemporary relationships. Primary psychopathic traits in men related to controlling mothers and avoidant attachment, whereas in women they related to uncaring fathers and both anxious and avoidant attachment. Secondary psychopathic traits in men were predicted by uncaring mothers and fathers, as well as anxious attachment, whereas in women, neither parental bonding nor attachment style were related. Results are discussed from an evolutionary, life history theory paradigm.
\end{abstract}

Keywords: attachment, life history strategy, parental bonding, primary and secondary psychopathy, sex differences

Life History Theory paradigm, a middle-level evolutionary theory, can explain how psychopathy affords genetic fitness in certain environments. Evidence suggests that psychopathy is a male-typical fast life history mating strategy (Glenn, Kurzban, \& Raine, 2011; Figueredo et al., 2006), defined by short-term mating orientation, unrestricted sociosexuality, and multiple sexual partners (Jonason, Li, Webster, \& Schmitt, 2009), and is adaptive in high morbidity-mortality environments (Glenn et al., 2011). Primary psychopathy has been suggested as the "successful" psychopathy as deceitful, ruthless, and manipulative behaviors are evidenced in business leaders (Babiak, Neumann, \& Hare, 2010; Hare, 1993) and other high-ranking professions (Mullins-Sweatt, Glover, Derefinko, Miller, \& Widiger, 2010). These traits may garner competitive advantage and signal to women as preferable in mate choice (Carter, Campbell,

Alyson Blanchard and Minna Lyons, Department of Psychological Sciences, University of Liverpool.

Correspondence concerning this article should be addressed to Alyson Blanchard, Department of Psychological Sciences, University of Liverpool, Eleanor Rathbone Building, Liverpool L69 7ZA, United Kingdom. E-mail: alyson .blanchard@liv.ac.uk
\& Muncer, 2014). Traits that expedite secondary psychopathy are risk taking, impulsivity, and short-term thinking (Figueredo et al., 2006). Despite adverse outcomes such as criminality and substance abuse (Hare, 2003), secondary psychopathy may also be an adaptation. The core difference between psychopathy subtypes is that primary psychopathy is an inherited "cheater strategy," developed in the environment of evolutionary adaptedness, whereas secondary psychopathy is a conditional adaptation to current deleterious environments (Mealey, 1995).

The adaptive quality of psychopathy in women is less understood because, by virtue of a higher level of parental investment, they are obligated to a slower life history strategy than men (Figueredo et al., 2006). However, indirect and relational aggression in primary psychopathy women (Vaillancourt \& Sunderani, 2011; Verona, Bresin, \& Patrick, 2013), and in both subtypes, higher levels of neuroticism (Lee \& Salekin, 2010), and low self-esteem and body shame (Visser, Pozzebon, Bogaert, \& Ashton, 2010) may constitute a female-typical fast life history strategy that avoids physical harm but promotes short-term mating. The presence of primary and secondary psychopathy in women may also similarly reflect the inherited/ 
conditional adaptation model proposed for men. Therefore, sex differences in psychopathy might be a consequence of the demands of the sex-typical, life history strategy that is selected for. However, the adaptive function of psychopathy in women is currently an under-investigated area of research.

There is evidence to suggest that environmental factors, namely adverse childhood experiences, are associated with secondary psychopathy via insecure attachment patterns (Craig, Gray, \& Snowden, 2013). According to attachment theory (Bowlby, 1969), innate adaptive mechanisms drive a child to seek physical and psychological proximity to the main caregiver. However, inconsistent affection, praise, and discipline from the parent will instill insecure attachment patterns that can be classed as avoidant and anxious (Bowlby, 1973). An adverse parenting style may serve as a proxy to a harsh environment to which the child must correspondingly react to. Such attachments may demonstrate developmental plasticity that cultivates adaptive attachment styles suited to a particular environment (e.g., those that are harsh and unpredictable; Ellis, Boyce, Belsky, Bakermans-Kranenburg, \& van Ijzendoorn, 2011). Attachment patterns also appear to manifest differently in men and women as a function of parental investment. For example, avoidant attachment, which is more common in men, can facilitate high mating effort. Women exhibit higher levels of anxious attachment, which may promote a heightened state of alert, helping them to monitor their partner who may be more likely to desert them when times are tough (Schmitt, 2003, although see Schmitt \& Jonason, 2015).

Indeed, the quality of bonding with each parent appears to influence men and women differently. For example, in women, poor quality or absent father-daughter relationships relate to behaviors characteristic of secondary psychopathy, such as susceptibility for substance abuse (Boyd, Ashcraft, \& Belgrave, 2006). Although adverse parenting, overall, appears to be a factor in the development of psychopathy in men, it is less known whether this is because of specific relationships with either the mother or father (Belsky, Steinberg, \& Draper, 1991). Genetic influences might also function differently according to sex and psychopathy subtype. For example, the link between psychopathic traits and biological criminal fathers is evidenced in men only (Beaver, Barnes, May, \& Schwartz, 2011), suggesting that psychopathy in men is under more genetic influence than in women. Evidently, both environmental and genetic factors are implicated in the development of psychopathy, but phenotypic outputs are different according to sex (Hicks, Vaidyanathan, \& Patrick, 2010; Krischer \& Sevecke, 2008).

The aim of the present study is to investigate sex differences in the manifestation of primary and secondary psychopathic traits in relation to recollections of childhood parental bonding experiences and current attachment patterns in a noninstitutional sample. We predict that the sex of the parent will have a different effect on primary and secondary psychopathic traits levels in the participants. Specifically, in line with the literature (Belsky et al., 1991), we also predict that suboptimal father-daughter bonding will relate to higher levels of either primary or secondary psychopathic traits in women. In addition, women are expected to express higher levels of anxious attachment compared with men, who will be more avoidant in their attachment type.

\section{Method}

\section{Participants and Procedure}

Three hundred sixty-two participants (185 men; mean age: $30.52, S D=10.00$ ) were recruited either from a student population at a U.K. North-West University ( $n=149)$, or community sample through social media advertising $(n=213)$ to participate in a survey on Personality Traits and Parental Bonding Experiences. The front page of the survey contained relevant ethics information, and the contact details of the researchers. After completing the survey, participants were thanked for their time, and presented with a debrief page.

\section{Measures}

Self-Report Psychopathy Scale (SRP-III). The SRP-III (Paulhus, Neumann, \& Hare, 2009) is a 64 -item, self-report questionnaire that provides a measure of psychopathic traits and behaviors in nonclinical populations. It consists of four subscales: "Callous affect," "Interpersonal manipulation," "Erratic lifestyle," and "Crimi- 
nal tendencies." Using a 5-point Likert scale, participants indicate to what degree they agree with statements such as "I think I could beat a lie detector" or "I like to see fist fights". "Callous affect" and "Interpersonal manipulation" are combined to obtain a primary psychopathic traits score; "Erratic life style" and "Criminal tendencies" combine to produce a secondary psychopathic traits score. Each score had good internal reliability for both sexes.

Parental Bonding Instrument (PBI). The PBI (Parker, Tupling, \& Brown, 1979) is a self-report 50-item questionnaire measuring retrospective evaluations of quality of maternal (25 items) and paternal (25 items) parenting received during childhood. Participants use a 4-point Likert scale to indicate how representative statements such as "Spoke to me in a warm and friendly voice" or "Tried to control everything I did" were of their parents during childhood. Two scales capture 'Mother care' and 'Father care,' and two others; 'Mother protection' and 'Father protection,' high values of which indicate overcontrolling behavior.

Relationship Scales Questionnaire (RSQ). We used Creasey and Ladd's (2005) Anxiety and Avoidant Scales that they adopted from the RSQ Scale (Griffin \& Bartholomew, 1994). Nineteen questions in total are used to measure anxious (11 questions) and avoidant (eight questions) attachment styles. Participants evaluate themselves on a 5-point Likert scale to indicate how strongly they agree with statements such as: "People are never there when you need them" or "I want emotionally close relationships." All RSQ scores had moderate to good internal reliability for both sexes.

\section{Results}

As expected, men scored significantly higher in primary and secondary psychopathic traits than women (see Table 1). Women scored significantly higher for recollections of overcontrolling mothers. There were no significant sex difference for any of the other parental bonding measures or anxious and avoidance attachment styles.

To explore the relationship between psychopathy subtypes, recollections of parental bonding, and attachment type in men and women, we conducted zero order and partial correlation analyses (see Table 2). We adjusted the alpha level to .001 to correct for multiple testing. Primary psychopathic traits in men were significantly associated with overcontrolling mothers and avoidant attachment; in women, they were associated with low-care fathers and anxious attachment. Secondary psychopathic traits in men were associated with low-care mothers and fathers; in women they were associated with overcontrolling fathers and anxious attachment. Partial correlation analyses, controlling each time for the variance in primary and secondary psychopathic traits, respectively, showed that primary psychopathic traits in men were not associated with any type of suboptimal bonding with each parent. However, low-care fathers were related to primary psychopathic traits in women. Further, both low-care mothers and fathers were associated with secondary psychopathic traits in men, and in women, none of the parental variables related to secondary psychopathic traits. Primary psychopathic traits were associated with avoidant attachment in men, and anxious attachment in women. Secondary

Table 1

Means, Standard Deviations, and Cronbach's Alpha for All Variables

\begin{tabular}{lccccrr}
\hline \multicolumn{1}{c}{ Variable } & Men & $\alpha$ & Women & $\alpha$ & \multicolumn{1}{c}{$t$} & \multicolumn{1}{c}{$d$} \\
\hline Primary psychopathy & $87.29(14.28)$ & .83 & $69.28(16.91)$ & .90 & $10.92^{\mathrm{a}}$ & 1.15 \\
Secondary psychopathy & $77.80(16.56)$ & .85 & $65.05(15.31)$ & .84 & $7.61^{\mathrm{a}}$ & .80 \\
Mother care & $35.28(7.28)$ & .80 & $36.57(7.77)$ & .85 & -1.63 & -.17 \\
Mother protection & $29.85(6.44)$ & .67 & $32.14(7.74)$ & .75 & $-3.04^{\mathrm{a}}$ & -.32 \\
Father care & $32.72(8.48)$ & .87 & $34.37(10.37)$ & .92 & -1.66 & -.17 \\
Father protection & $29.10(7.72)$ & .77 & $29.95(10.22)$ & .85 & -.90 & -.09 \\
Anxious & $28.08(9.19)$ & .90 & $28.49(10.11)$ & .90 & -.40 & -.04 \\
Avoidant & $24.79(4.90)$ & .65 & $23.57(5.14)$ & .67 & $1.75^{\mathrm{a}}$ & .24 \\
\hline
\end{tabular}

${ }^{\text {a }}$ Significant difference between men and women, $p<.01$. 
Table 2

Zero Order Correlations Between All Variables for Men and Women

\begin{tabular}{|c|c|c|c|c|c|c|}
\hline \multirow[b]{2}{*}{ Variable } & \multicolumn{3}{|c|}{ Primary psychopathy } & \multicolumn{3}{|c|}{ Secondary psychopathy } \\
\hline & Men & Women & $z$ & Men & Women & $z$ \\
\hline Mother care & -.15 & -.17 & .19 & $-.31^{* *}$ & -.14 & $-1.69^{*}$ \\
\hline Mother protection & $.21^{* *}$ & .00 & 2.01 & .14 & -.07 & $1.99^{*}$ \\
\hline Father care & -.05 & $-.26^{* *}$ & -2.98 & $-.22^{* *}$ & $-.20^{* *}$ & -.20 \\
\hline Father protection & .09 & .01 & $.76^{*}$ & .11 & -.04 & 1.42 \\
\hline Anxious & .06 & $.42^{* * *}$ & $-3.66^{* * *}$ & .17 & $.26^{* *}$ & -.89 \\
\hline Avoidant & $.22^{* *}$ & .15 & .68 & -.08 & .00 & -.76 \\
\hline \multicolumn{7}{|c|}{ Partial correlations between all variables for men and women } \\
\hline Mother care & .02 & -.11 & 1.23 & $-.27^{* * *}$ & -.04 & $2.99^{* *}$ \\
\hline Mother protection & .17 & .05 & 1.15 & .03 & -.08 & 1.04 \\
\hline Father care & .09 & $-.18^{*}$ & $2.57^{* *}$ & -.23 & -.05 & $2.68^{* *}$ \\
\hline Father protection & .03 & .05 & -.19 & .08 & -.06 & 1.32 \\
\hline Anxious & -.05 & $.34^{* *}$ & $-3.81^{* * *}$ & .17 & .01 & 1.52 \\
\hline Avoidant & $.31^{* * *}$ & .19 & 1.21 & $-.25^{* *}$ & -.12 & -1.27 \\
\hline
\end{tabular}

Note. $z$ is Fisher's $z$ to compare dependent correlations.

${ }^{*} p<.05$. ${ }^{* *} p<.01$.

psychopathic traits in men related to reduced avoidant attachment, whereas in women, neither attachment style was associated with secondary psychopathic traits.

To look at the relative contribution of each variable to primary psychopathic traits in both sexes, we conducted linear multiple regression, where secondary psychopathic traits were added as a predictor at Step 1, low-care mothers at Step 2, overcontrolling mothers at Step 3, low-care fathers at Step 4, overcontrolling fathers at Step 5, anxious attachment at Step 6, and avoidant attachment at Step 7 (see Table 3). In men, the overall model accounted for $37 \%$ of the variance in primary psychopathic traits. Secondary psychopathic traits, overcontrolling mothers, and avoidant attachment significantly added to the model. However, the model was not improved by adding low-care mothers, low-care fathers, overcontrolling fathers, or anxious attachment. Secondary psychopathic traits, overcontrolling mothers, and avoidant attachment emerged as significant predictors.

In women, the overall model explained $46 \%$ of the variance in primary psychopathic traits. Secondary psychopathic traits, low care fathers, and anxious and avoidant attachment added significantly to the model. However, the model was not improved by adding either low-care or overcontrolling mothers, or overcontrolling fa-

Table 3

Stepwise Regression Analysis of Primary Psychopathy in Men and Women on All Independent Variables

\begin{tabular}{|c|c|c|c|c|c|c|c|c|c|c|}
\hline \multirow[b]{2}{*}{ Variable entered } & \multicolumn{5}{|c|}{ Men } & \multicolumn{5}{|c|}{ Women } \\
\hline & $R$ & $F$ to enter & $\Delta$ in $R^{2}$ & $\beta$ & $t$ & $R$ & $F$ to enter & $\Delta$ in $R^{2}$ & $\beta$ & $t$ \\
\hline & .63 & & & & & .70 & & & & \\
\hline 1. Secondary psychopathy & & 77.68 & $.30^{* * *}$ & .57 & $9.17^{* * *}$ & & 102.70 & $.37^{* * *}$ & .51 & $8.78^{* *}$ \\
\hline 2. Low care mothers & & 38.70 & .01 & -.04 & -.53 & & 52.83 & .01 & -.02 & -.29 \\
\hline 3. Over controlling mothers & & 28.39 & $.02^{*}$ & .18 & $2.25^{*}$ & & 35.04 & .01 & .01 & -.03 \\
\hline 4. Low care fathers & & 21.65 & .01 & .14 & 1.83 & & 27.94 & $.02 *$ & -.12 & -1.86 \\
\hline 5. Over controlling fathers & & 18.10 & .01 & -.09 & -1.13 & & 22.97 & .01 & .06 & .81 \\
\hline 6. Anxious attachment & & 15.11 & .01 & .01 & .01 & & 24.21 & $.06^{*}$ & .27 & $4.55^{* *}$ \\
\hline 7. Avoidant attachment & & 16.56 & $.06^{* * *}$ & .25 & $4.13^{* *}$ & & 22.63 & $.02^{* *}$ & .15 & $2.75^{* *}$ \\
\hline
\end{tabular}

${ }^{*} p<.05 . \quad{ }^{* *} p<.01$. 
thers. Secondary psychopathic traits, anxious attachment, and avoidant attachment emerged as significant predictors, whereas low-care fathers did not.

To look at the relative contribution of each variable to secondary psychopathic traits in both sexes, primary psychopathic traits were added as a predictor at Step 1, low-care mothers at Step 2, overcontrolling mothers at Step 3, low-care fathers at Step 4, overcontrolling fathers at Step 5, anxious attachment at Step 6, and avoidant attachment at Step 7 (see Table 4). For secondary psychopathic traits in men, the overall model accounted for $37 \%$ of the variance, $29 \%$ of which was contributed to by primary psychopathic traits which also emerged as a significant predictor. Low care mothers improved the model and significantly predicted secondary psychopathic traits as did avoidant attachment. The model was not improved by overcontrolling mothers, low-care and overcontrolling fathers, or anxious attachment. This indicates that the influence of low-care mothers and avoidant attachment are important in the development of secondary psychopathic traits in men. In women, apart from primary psychopathic traits which accounted for $36 \%$ of the model, none of the other variables made a significant contribution to the model.

\section{Discussion}

In this study, we have added to the current literature (Mack, Hackney, \& Pyle, 2011) regarding influences of negative parenting styles in the expression of primary and secondary psychopathic traits. Our results indicate that these influences and their outcomes may function in relation to inequity in parental investment between men and women. We found that primary psychopathic traits related uniquely to controlling mothers and avoidant attachment in men, and low-care fathers and anxious and avoidant attachment types in women. In contrast, secondary psychopathic traits were predicted by anxious attachment and uncaring mothers, and were associated with low care fathers in men, whereas parental bonding experiences and attachment had no relationship to secondary psychopathic traits in women. These findings may partially support the argument that secondary psychopathy is an environmentally derived phenocopy of primary psychopathy, which is an inherited male-typical cheater strategy (Glenn et al., 2011; Mealey, 1995), because maternal overprotection aside, recalled parenting had little influence on men's primary psychopathy scores. Nevertheless, the association with overcontrolling mothers could be an example of passive gene-environment interaction, where controlling behavior is inherited as a primary psychopathic trait whose expression is reinforced by the mother's behavior within the rearing environment (Loney, Huntenburg, CountsAllan, \& Schmeelk, 2007). Overall, this could indicate a larger genetic component for this trait in men. Primary psychopathic traits in men also related to avoidant attachment, which makes sense knowing that both avoidant attachment (Del Giudice, 2009) and primary psychopathy (Jonason et al., 2009; Ross \& Rausch, 2001) have a relationship with male mating strategies characterized by low commitment, and high competition for status.

Table 4

Stepwise Regression Analysis of Secondary Psychopathy in Men and Women on All Independent Variables

\begin{tabular}{|c|c|c|c|c|c|c|c|c|c|c|}
\hline \multirow[b]{2}{*}{ Variable entered } & \multicolumn{5}{|c|}{ Men } & \multicolumn{5}{|c|}{ Women } \\
\hline & $R$ & $F$ to enter & $\Delta$ in $R^{2}$ & $\beta$ & $t$ & $R$ & $F$ to enter & $\Delta$ in $R^{2}$ & $\beta$ & $t$ \\
\hline & .63 & & & & & .62 & & & & \\
\hline 1. Primary psychopathy & & 77.68 & $.30^{* *}$ & .57 & $9.17^{* * *}$ & & 102.70 & $.37^{* *}$ & .61 & $8.78^{* *}$ \\
\hline 2. Low care mothers & & 49.17 & $.05^{* *}$ & -.13 & -1.77 & & 51.30 & 0 & -.06 & -.87 \\
\hline 3. Over controlling mothers & & 32.71 & 0 & -.08 & -.99 & & 34.88 & .01 & -.09 & -1.15 \\
\hline 4. Low care fathers & & 24.93 & .01 & -.13 & -1.68 & & 26.15 & 0 & -.05 & -.65 \\
\hline 5. Over controlling fathers & & 20.61 & .01 & .09 & 1.08 & & 20.80 & 0 & .01 & .07 \\
\hline 6. Anxious attachment & & 17.38 & 0 & .04 & .59 & & 17.23 & 0 & -.02 & -.25 \\
\hline 7. Avoidant attachment & & 16.70 & $.03^{* *}$ & -.18 & $-2.89^{* *}$ & & 15.36 & .01 & -.11 & -1.71 \\
\hline
\end{tabular}

*** $p<.01$. 
The relationship between low-care fathers and primary psychopathic traits in women would be partly expected considering that father absence during childhood promotes a range of internalizing behaviors that covary with femaletypical psychopathic traits (Belsky et al., 1991) and fast life history strategies (Visser et al., 2010). Again, this relationship may also be indicative of passive gene-environment interaction if low-care is taken to mean unempathetic. Although internalizing behaviors appear to pertain more to secondary psychopathy, the distinction between psychopathy subtypes in women is less distinct and can therefore explain this finding (Lehmann \& Ittel, 2012; Rogstad \& Rogers, 2008). Indeed, the relationship between primary psychopathic traits and anxious attachment type may be indicative of higher levels of anxiety that are associated with primary psychopathy in women (Hicks et al., 2010; Lee \& Salekin, 2010). Therefore, internalizing behaviors such as neuroticism, low self-esteem, and indirect aggression, in tandem with anxious and avoidant attachment, could together operate as a successful fast, life history strategy for two reasons. First, by fostering short-term mating behaviors, and, second, by heightening a woman's awareness to danger, reducing the likelihood of physical harm to her or her children while she pursues other mates.

Our findings for secondary psychopathic traits in men complement research that consistently evidences adverse home environments as a source of influence in the expression of secondary psychopathy in forensic and normative samples (e.g., Mack et al., 2011; Poythress, Skeem, \& Lilienfeld, 2006). However, in contrast to primary psychopathic traits, uncaring parents are more important than an overcontrolling mother in the development of secondary psychopathic traits, which may indicate multiple environmental influences rather than genetic inheritance. This would also support the argument that secondary psychopathy is an environmentally derived "phenocopy" of primary psychopathy, which functions as an adaptive developmental response to unfavorable circumstances (Mealey, 1995). Indeed, behavioral plasticity (Ellis et al., 2011) and attachment theory (Bowlby, 1969; Frodi, Dernevik, Sepa, Philipson, \& Bragesjö, 2001) would predict the relationship found here between secondary psychopathic traits and anxious attachment type, and might explain why secondary psychopathic individuals are significantly more anxious, rather than avoidant in their behavior.

The absence of any notable influential factor in secondary psychopathic traits in women is interesting considering that previous research clearly implicates the effect of adverse childhood experiences (Krischer \& Sevecke, 2008; Hicks et al., 2010). Women who exhibit secondary psychopathic behavior may have been subjected to other influencing factors not measured in this study. These could include more specific adverse childhood experiences that do not pertain to parental bonding, such as physical abuse and parental conflict (Belsky et al., 1991). Alternatively, a conglomerate of these factors might be necessary, while individual differences might exacerbate or attenuate certain influences. Furthermore, research shows that the expression of primary and secondary psychopathy in women can vary as a response to cultural factors (Neumann, Schmitt, Carter, Embley, \& Hare, 2012). In this situation also, it might serve one woman to employ an anxious attachment type, or another woman, an avoidant attachment type. Thus a heterogeneous environmental input might result in a heterogeneous output of differently tailored adaptive attachment types, such that no particular one is associated with secondary psychopathy. Overall, these findings support the notion that, although the precise dynamics are less clear, secondary psychopathy in women is more environmentally influenced and as such, may demonstrate adaptive developmental plasticity.

Although convenient, self-report measures are subject to self-bias. Consideration should also be given to the fact that psychopathic individuals are skilled at deception (Seto, Khattar, Lalumière, \& Quinsey, 1996). Scores for the PBI and RSQ could therefore be likewise distorted. Furthermore, recollections of childhood experiences are likely affected by the accuracy of recall. Parental bonding is only one measure of many different childhood experiences that are potential influences in the development of psychopathy. Similarly, attachment styles may be more discrete than simply anxious or avoidant. Nevertheless, this study has demonstrated sex differences in the developmental trajectory of primary and secondary psychopathy and, by utilizing life history theoretical perspective, has suggested that these differences are 
necessary for short-term mating strategies that are determined by sexually differentiated levels of parental investment.

\section{References}

Babiak, P., Neumann, C. S., \& Hare, R. D. (2010). Corporate psychopathy: Talking the walk. Behavioral Sciences \& the Law, 28, 174-193.

Beaver, K. M., Barnes, J. C., May, J. S., \& Schwartz, J. A. (2011). Psychopathic personality traits, genetic risk, and gene-environment correlations. Criminal Justice and Behavior, 38, 896-912. http://dx.doi.org/10.1177/0093854811411153

Belsky, J., Steinberg, L., \& Draper, P. (1991). Childhood experience, interpersonal development, and reproductive strategy: And evolutionary theory of socialization. Child Development, 62, 647-670. http://dx.doi.org/10.2307/1131166

Bowlby, J. (1969). Attachment and loss: Vol. 1. Attachment. New York, NY: Basic Books.

Bowlby, J. (1973). Attachment and loss: Vol. 2. Separation. New York, NY: Basic Books.

Boyd, K., Ashcraft, A., \& Belgrave, F. Z. (2006). The Impact of mother-daughter and father-daughter relationships on drug refusal self-efficacy among African American adolescent girls in urban communities. Journal of Black Psychology, 32, 29-42. http://dx.doi.org/10.1177/0095798405280387

Carter, G. L., Campbell, A. C., \& Muncer, S. (2014). The Dark Triad personality: Attractiveness to women. Personality and Individual Differences, 56, 57-61.

Craig, R. L., Gray, N. S., \& Snowden, R. J. (2013). Recalled parental bonding, current attachment, and the triarchic conceptualisation of psychopathy. Personality and Individual Differences, 55, 345350. http://dx.doi.org/10.1016/j.paid.2013.03.012

Creasey, G., \& Ladd, A. (2005). Generalized and specific attachment representations: Unique and interactive roles in predicting conflict behaviors in close relationships. Personality and Social Psychology Bulletin, 31, 1026-1038. http://dx.doi .org/10.1177/0146167204274096

Del Giudice, M. (2009). Sex, attachment, and the development of reproductive strategies. Behavioral and Brain Sciences, 32, 1-21. http://dx.doi .org/10.1017/S0140525X09000016

Ellis, B. J., Boyce, W. T., Belsky, J., BakermansKranenburg, M. J., \& van Ijzendoorn, M. H. (2011). Differential susceptibility to the environment: An evolutionary-Neurodevelopmental theory. Development and Psychopathology, 23, 7-28. http://dx.doi.org/10.1017/S0954579410000611

Figueredo, A., Vasquez, G., Brumbach, B. H., Schneider, S. M. R., Sefcek, J. A., Tal, I. R., . . . Jacobs, W. (2006). Consilience and life history theory: From genes to brain to reproductive strategy. Developmental Review, 26, 243-275. http:// dx.doi.org/10.1016/j.dr.2006.02.002

Frodi, A., Dernevik, M., Sepa, A., Philipson, J., \& Bragesjö, M. (2001). Current attachment representations of incarcerated offenders varying in degree of psychopathy. Attachment \& Human Development, 3, 269-283. http://dx.doi.org/10.1080/ 14616730110096889

Glenn, A. L., Kurzban, R., \& Raine, A. (2011). Evolutionary theory and psychopathy. Aggression and Violent Behavior, 16, 371-380. http://dx.doi .org/10.1016/j.avb.2011.03.009

Griffin, D. W., \& Bartholomew, K. (1994). The metaphysics of measurement: The case of adult attachment. In K. Bartholomew \& D. W. Griffin (Eds.), Advances in personal relationships: Vol. 5, Attachment processes in adulthood (pp. 17-52). London, UK: Jessica Kingsley Publishers.

Hare, R. D. (1993). Without conscience: The disturbing world of the psychopaths amongst us. New York, NY: Guilford Press.

Hare, R. D. (2003). The Hare psychopathy checklistrevised (2nd ed.). Toronto, Canada: Multi-Health Systems, Inc.

Hicks, B. M., Vaidyanathan, U., \& Patrick, C. J. (2010). Validating female psychopathy subtypes: Differences in personality, antisocial and violent behavior, substance abuse, trauma, and mental health. Personality Disorders: Theory, Research, and Treatment, 1, 38-57. http://dx.doi.org/10 $.1037 / \mathrm{a} 0018135$

Jonason, P. K., Li, N. P., Webster, G. D., \& Schmitt, D. P. (2009). The Dark Triad: Facilitating a shortterm mating strategy in men. European Journal of Personality, 23, 5-18. http://dx.doi.org/10.1002/ per.698

Krischer, M. K., \& Sevecke, K. (2008). Early traumatization and psychopathy in female and male juvenile offenders. International Journal of Law and Psychiatry, 31, 253-262. http://dx.doi.org/10 .1016/j.ijlp.2008.04.008

Lee, Z., \& Salekin, R. T. (2010). Psychopathy in a noninstitutional sample: Differences in primary and secondary subtypes. Personality Disorders: Theory, Research, and Treatment, 1, 153-169. http://dx.doi.org/10.1037/a0019269

Lehmann, A., \& Ittel, A. (2012). Aggressive behavior and measurement of psychopathy in female inmates of German prisons-A preliminary study. International Journal of Law and Psychiatry, 35, 190-197. http://dx.doi.org/10.1016/j.ijlp.2012.02 .007

Loney, B. R., Huntenburg, A., Counts-allan, C., \& Schmeelk, K. M. (2007). A preliminary examination of the intergenerational continuity of maternal psychopathic features. Aggressive Behavior, 33, 14-25. 
Mack, T. D., Hackney, A. A., \& Pyle, M. (2011). The relationship between psychopathic traits and attachment behavior in a non-clinical population. Personality and Individual Differences, 51, 584588. http://dx.doi.org/10.1016/j.paid.2011.05.019

Mealey, L. (1995). Primary sociopathy (psychopathy) is a type, secondary is not. Behavioral and Brain Sciences, 18, 579-599. http://dx.doi.org/10 .1017/S0140525X00040024

Mullins-Sweatt, S. N., Glover, N. G., Derefinko, K. J., Miller, J. D., \& Widiger, T. A. (2010). The search for the successful psychopath. Journal of Research in Personality, 44, 554-558. http://dx .doi.org/10.1016/j.jrp.2010.05.010

Neumann, C. S., Schmitt, D. S., Carter, R., Embley, I., \& Hare, R. D. (2012). Psychopathic traits in females and males across the globe. Behavioral Sciences \& the Law, 30, 557-574. http://dx.doi .org/10.1002/bsl.2038

Parker, G., Tupling, H., \& Brown, L. B. (1979). A parental bonding instrument. British Journal of Medical Psychology, 52, 1-10. http://dx.doi.org/10 $.1111 / j .2044-8341.1979 . t b 02487 . x$

Paulhus, D. L., Neumann, C. S., \& Hare, R. D. (2009). Manual for the Self-Report Psychopathy scale. Toronto, Canada: Multi-Health Systems.

Poythress, N. G., Skeem, J. L., \& Lilienfeld, S. O. (2006). Associations among early abuse, dissociation, and psychopathy in an offender sample. Journal of Abnormal Psychology, 115, 288-297. http:// dx.doi.org/10.1037/0021-843X.115.2.288

Rogstad, J. E., \& Rogers, R. (2008). Gender differences in contributions of emotion to psychopathy and antisocial personality disorder. Clinical Psychology Review, 28, 1472-1484. http://dx.doi.org/ 10.1016/j.cpr.2008.09.004

Ross, S. R., \& Rausch, M. K. (2001). Psychopathic attributes and achievement dispositions in a col- lege sample. Personality and Individual Differences, 30, 471-480. http://dx.doi.org/10.1016/ S0191-8869(00)00038-6

Schmitt, D. E. (2003). Are men universally more dismissing than women? Gender differences in romantic attachment across 62 cultural regions. Personal Relationships, 10, 307-331. http://dx.doi .org/10.1111/1475-6811.00052

Schmitt, D. P., \& Jonason, P. K. (2015). Attachment and sexual permissiveness: Exploring differential associations across sexes, cultures, and facets of short-term Mating. Journal of Cross-Cultural Psychology, 46, 119-133. http://dx.doi.org/10.1177/ 0022022114551052

Seto, M. C., Khattar, N. A., Lalumière, M. L., \& Quinsey, V. L. (1997). Deception and sexual strategy in psychopathy. Personality and Individual Differences, 22, 301-307.

Vaillancourt, T., \& Sunderani, S. (2011). Psychopathy and indirect aggression: The roles of cortisol, sex, and type of psychopathy. Brain and Cognition, 77, 170-175. http://dx.doi.org/10.1016/j .bandc.2011.06.009

Verona, E., Bresin, K., \& Patrick, C. J. (2013). Revisiting psychopathy in women: Cleckley/Hare conceptions and affective response. Journal of $A b$ normal Psychology, 122, 1088-1093. http://dx.doi .org/10.1037/a0034062

Visser, B. A., Pozzebon, J. A., Bogaert, A. F., \& Ashton, M. C. (2010). Psychopathy, sexual behavior, and esteem: It's different for girls. Personality and Individual Differences, 48, 833-838. http://dx .doi.org/10.1016/j.paid.2010.02.008

Received April 9, 2015

Revision received October 22, 2015 Accepted November 3, 2015 